\title{
Uncoupling protein-2 and non-alcoholic fatty liver disease
}

\section{Citation}

Baffy, Gyorgy. 2005. "Uncoupling Protein-2 and Non-Alcoholic Fatty Liver Disease." Frontiers in Bioscience 10 (1-3): 2082. doi:10.2741/1683.

\section{Published Version}

doi:10.2741/1683

\section{Permanent link}

http://nrs.harvard.edu/urn-3:HUL.InstRepos:34864846

\section{Terms of Use}

This article was downloaded from Harvard University's DASH repository, and is made available under the terms and conditions applicable to Other Posted Material, as set forth at http:// nrs.harvard.edu/urn-3:HUL.InstRepos:dash.current.terms-of-use\#LAA

\section{Share Your Story}

The Harvard community has made this article openly available.

Please share how this access benefits you. Submit a story.

\section{Accessibility}




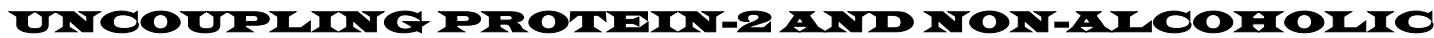
FEMTY WIVER DIEAESE

Györog Bafry

Liver IResearch Center, Division of Gastroenterology, Rhode Island Itospital and Brovin Medical School, Providence, IRT O2903

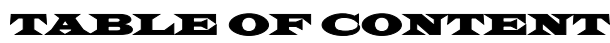

1. Abstract

2. Introduction

3. Uncoupling protein-2: General considerations 3.1. Ilistorical perspectives

3.2. Expectations and uncertainties

3.3. UCP2 and mitochondmial IROS production

3.4. Tissue distribution of UCPQ

4. NAILD and the 'first hit': Is UCP2 linked to steatosis? 4.1. Development of steatosis

4.2. Regulation of UCAP expression by fatty acids

4.3. Impact of hepatic UCP2 expression on steatosis

5. NAFID and the 'second hit': Is UCPP linked to steatohepatitis?

5.1. Oxidative stress and mitochondrial dysfunction in NAFID

5.2. NAFID and cell-specific changes in hepatic UCIP expression

5.3. UCP2 and hepatocellular energy status in NAFID

6. NAFID and late events: Is UCPQ linked to liver

cancer?

6.1. Obesity and liver cancer

6.2. UCP2 as a modulator of apoptosis

6.3. UCP2 and cancer cell adaptation to oxidative stress

7. Conclusions and perspectives

8. Aclunoviledgments

9. References

\section{ABETREOT}

Non-alcoholic fatty liver disease (NAFID) has become the most common form of hepatic disorders in the developed world. NAFID is part of the metabolic syndrome with insulin resistance as a primary underlying derangement. The natural history of NAFID may extend from simple steatosis over steatohepatitis into ciprosis and hepatocellular carcinoma. Among numerous factors shaping these transitions, uncoupling protein-2 (UCP2) may theoretically contribute to every stage of this disease. UCP2 is a recently identified fatty acid-responsive mitochondrial inner membrane carrier protein shoving wide tissue distribution with a substantially increased presence in fatty liver. The biological functions of UCP2 are not fully elucidated and the giceater part of our current knowiledge has been obtained from animal experiments. These data suggest a role for UCP2 in lipid metabolism, mitochondrial bioenergetics, oxidative stress, apoptosis, and exen carcinoǵenesis. A vailable evidence is revievred and nevy concepts are considered to appraise the potential role of UCP 2 in the pathogenesis of NAFID.

\section{INTEODUOTION}

Obesity has reached epidemic proportions in the economically developed worldand reshaped the landscape of medicine (1). Obesity is the gatevyay to chronic conditions with debilitating consequences such as type 2 diabetes, hypertension, and eleyated plasma lipid levels (2). These conditions are termed collectively as the metabolic syndrome with insulin resistance as 
common underlying derangement (3). Hepatic

manifestations of the metabolic syndrome have become kmowin as non-alcoholic fatty liver disease (NAIID) (4). Although the 'non-alcoholic' connotation is not

particularly fortunate, it indicates that NAFLD is, despite a separate etiology, difficult to distinguish from alcoholic liver disease (5). In Mestern countries, NAILD has become by far the most common form of any liver disease with a $14 \%$ to $24 \%$ estimated prevalence in the general population (6-8).

NAFLD has been classified into three major forms, primarily identified by histology as successive stages that may progress into end-stage liver disease $(5,9)$. IVIst patients with NAFLD have pure macrovesicular steatosis yith minimal or no clinical symptoms and no perceivable progression (5). Consequently, this initial stage of NAFLD is not alvays considered a disease. There is evidence, hovyever, that $20 \%$ to $30 \%$ of these individuals eventually progress into the next stage of NAFLD, termed non-alcoholic steatohepatitis (NASII) and characterized by more frequent clinical symptoms, laboratory abnormalities, distinct histological changes, and a $15 \%$ to $20 \%$ chance of further progiression into ciproosis and eventually into hepatocellular carcinoma (I)C) $(9,10)$.

The pathogenesis of NAIFD and the predictors of its progóression remain incompletely understood. The 'turo hit' hypothesis proposed by Day and James has become a widely accepted framework to guide current research in this area (II). Accordingly, the 'first hit' is a buildup of lipids in the liver along with the development of insulin resistance. These changes may provide the basis for progressive liver disease in response to a 'second hit' in which a yariety of mechanisms, some of them selfperpetuating, have been implicated (12, 13). In the late phase of INALD, development of cirihosis and IICO may exhibit distinct sets of pathologic processes.

This revievy will focus on the potential contribution of uncoupling protein-2 (UCP2), a novel member of the mitochondrial inner membrane carrier protein family (14, 15), to the pathogenesis of NAIID. Although UCIP is an appealing molecular target for seyeral reasons discussed below, its biological functions remain poorly defined and we are left with much speculation in this regard. Nonetheless, theoretical considerations and experimental data suggest that UCP2 may have a role in yarious stages of NAIID and it is therefore of interest to revievy current knoviledge on UCP2 and outline potential directions for further research.

3. UNOOUPIUNG PROMAIN-2: GHNAIRAL OONEIDERETIONE

\subsection{Iletorical perepectives}

Uncoupling (i.e., disconnection of ATP symthesis from mitochondrial cespiration) has long been a tempting target in the treatment of obesity. In fact, dinitrophenol, a potent mitochondrial uncoupling compound, yas introduced in the 1930 's as a successful anti-obesity agent, just to be withdravin from the market due to its yery narrow therapeutic range and occasionally fatal side effects (16). The subject of uncoupling uvas later revitalized by two lines of research. In 1961 , Peter Mitchell published his groundbrealxing chemiosmotic theory, which has defined our current understanding on the mechanism of oxidative phosphorylation (17). The respiratory or electron transport chain (ETC) has four large multi-subunit enzyme complexes embedded in the 
inner mitochondwial membrane along with ATP symthase (Figure 1). Electrons are domated to the ETO by NADI (reduced nicotinamide adenine dinucleotide) and succinate and passed along the complexes to ultimately reduce molecular oxygen to vyater at complex IV (cytochrome c oxidase). According to Mitchell's theory, this series of highly exergonic reactions provides energy for the outwrard translocation of protons from the mitochondrial matrix into the intermembrane space to create an electrochemical orradient across the inmer membrame (17). This mitochondrial membrane potential $(\Delta \Psi \mathrm{m})$, also called proton-motive force, will then drive ATP synthesis thwough the controlled return of protons into the matrix (17).

The chemiosmotic theory has been yalidated by many experiments (18). It was also noted, hovever, that oxidative phosphorylation is never $100 \%$ efficient and this partial uncoupling is believed to be an inherent characteristic of mitochondrial respiration. In fact, a significant portion of consumed oxygen is 'viasted' and dissipated as heat energy in all examined cell types (19). A backflow of protons independent of ATP 5 ynthesis accounts for this portion of oxygen consumption and is termed proton leak (19). The relationship between $\Delta \Psi \mathrm{m}$ and uncoupling is non-ohmic, i.e., higher $\Delta \Psi$ m yalues are associated with disproportionately higher proton lealk (20). Proton lealx can be estimated by the rate of respiration duwing resting or 'state 4' conditions, when ATP synthesis is inhibited either directly (e.g., by oligomycin) or by substrate unayailability (lack of ADIP) (20). Proton leak in hepatocytes of both endotherm and ectotherm species accounts for 15 to $40 \%$ of total oxygen consumption (20). In addition to inherent biophysical properties of the inmer membrane Cbasal proton conductance), proton lealx may result from the action of specialized carrier proteins (inducible proton conductance) (20). Uncoupling protein (UCP or thermogemin, later renamed UÖPI), a mediator of coldadapted thermogenesis, performs precisely this function in the mitochondria of brown adipose tissue (BAT) and its identification provided another milestone in bioenergetics (21). UCPl has been unequivocally proven to be a physiologic mediator of proton lealk (21), although this action is restricted to BAT and UCPl therefore plays a limited role in humans where BAT becomes virtually absent by adulthood.

\subsection{Expectations and uncertainties}

The search for additional uncoupling proteins was successful in 1997 , when UCP2 was identified by cloning strategies in the mouse and human genomes, based on its partial sequence homology with UClPI (22, 23). UCI3 yras described almost simultaneously and 2 further members of the UCP subfamily of mitochondrial anion carrier proteins (UOPA and UOCP5) soon follovied suit (24). The ucp 2 gene yas mapped to chromosome 7 in mouse and to the syntenic chromosome region 11 gl 3 in man (22, 23). UCP2 mRNA is transcribed from the distal 6 of 8 existing exoms of ucp 2 gene (25). UCP2 in humans is a 308 amino acid protein with molecular weight of 33 lxDa and a $59 \%$ amino acid identity to UCPI (22, 23). Consequently, the structure of UCP2 protein is yery similar to that of UCPI and is remarkably urell conserved between different species. Alxin to all members of the mitochondrial cariop family, UGPQ contains six alphahelical spanners with a total of three mitochondwial energy transfer protein signature regions and is embedded in the mitochondrial inmer membrane where it is thought to function as a homodimer (25). 
To understand the biological function(s) of UCP2, a link of UCP2 to energy metabolism uas tested in a hope to find nevy ways to treat obesity (26). The high homology with UCPI suggosested that UCIP2 might also mediate pioton leak, only to act on a larger number of targets based on its wide tissue distribution (see belovy). Moreover, the ucpe gene was found in proximity to a cluster of at least 5 additional genes related to energy homeostasis and obesity (22). A common polymorphism in the promoter region of ucp 2 gene (-866A/G) was shown to enhance its transcriptional activity and UCP2 has been linked to increased prevalence of obesity (27), although this association could not be confirmed by others ( 28 ).

The physiological role of U CPQ-mediated proton leak also remains a matter of debate (20). UCP2 induced proton conductance in yeast only urhen expressed in amounts a magnitude over the highest known physiological concentrations and still could not account for the degree of basal uncoupling seen in mammalian mitochondria (29). The amount of UCPl, the only uncoupling protein that beyond doubt has been proven to mediate proton lealk of physiological releyance, is exceptionally high in BAT and may reach $" 5 \%$ of total mitochondrial protein content (30). UCP2 is presemt to some degree in virtually every mammalian tissue; hoverer, the amount of UCP2 is usually one to two magnitudes smaller urhen compared to UCPI abundance in BAT (30). For instance, the presence of UCP2 in spleen, a tissue in which UCP2 is relatively highly expressed, was estimated to be 160 fold less than UOCPI in BAT (31). Consequently, contribution of UCP2 to proton leak is likely to be much more modest, perhaps causing a few m $Y$ decrease in $\Delta \Psi \mathrm{m}$. This may be, nevertheless, sufficient to result in important consequences as discussed beloy.

\subsection{UOP2 and mitochondial IROE production}

For most electrons that trayel down the respiratory chain, cytochrome coxidase (complex IY) is the final destination where molecular oxygen is conyerted into water by four-electron reduction (Figure 1). Some 'stray' electrons, hovever, may convert oxygen into superoxide anion by partial (one-electron) reduction at earlier junctures of mitochondrial respiration complex I or complex III) (32). There are varying estimates as to what fraction of the totally consumed oxygen would yield superoxide (from 0.15\% to a fexy percents) (33), but this fraction may significantly increase in certain conditions. Any major imbalance between outward proton translocation (gradient buildup) and ATP synthesis (gradient consumption) is reflected in an increased $\Delta \Psi \mathrm{m}$. IVitochondrial hyperpolarization prolongs the half-life of mobile electron carriers that will mediate partial reduction of oxygen and generate superoxide (34). This mechanism may be particularly releyant to obesity and other metabolic conditions characterized by fuel surplus that yields excess NADII.

Several years before the identification of novel uncoupling proteins, in vitro experiments using liver mitochondria demonstrated that ROS production correlates with $\Delta \Psi$ m and both can be reduced by artificial uncouplers such as dinitrophenol (35). Subsequently, the concept of mild uncoupling has been introduced, which predicted the existence of a protein-regulated proton leak with the main purpose of controlling mitochomdrial oxidative stress (34, 36). It has been demonstrated that small changes of $\Delta \Psi \mathrm{m}$ have large effects on rates of superoxide production (37, 38). This indicates at least the 
feasibility of such a regulating role for UCP2 often present in insubstantial amounts.

The idea of UCP2 as a negative regulator of IROS production has been successfully tested in a variety of experimental settings. In many studies, absence of UCP2 yas associated with increased oxidative stress (39-41). These experiments often implicated the role of monocyte/macrophage cells in which UCP2 expression has been repeatedily found to be high. The first evidence yas obtained on nonparenchymal liver cells in which GDP, a natural inhibitor of UCP2, resulted in elevated $\Delta \Psi$ m and hydrogen peroxide production (39). This notion yras further supported by in wixo experiments in which peritoneal macrophages of UCP2-/-mice produced $80 \%$ more ROS than wild type controls, thus enabling these animals to survive Foxoplasma infection (4)

Strategies providing cell protection from oxidative stress by enhanced UCP2 expression have also been successful. Oyerexpression of UCP2 in cultured neonatal cardiomyocytes made these cells more resistant to oxidative stress and mitigated the detrimental loss of $\Delta \Psi \mathrm{m}$ upon exposure to hydrogen peroxide (42). Similarly, cultured cortical neurons overexpressing UCIP and brain tissue of UCF2-transgenic mice exhibited increased tolerance against glucose and oxygen deprivation, conditions that typically cause neuronal cell death (43).

Of note, uncoupling proteins and mitochondrial IROS appear to have a reciprocal relationship. Exposure of isolated mitochondria to superoxide results in increased proton conductance and correlates with tissue expression of UCPI, UCP2, and UCP3 (44). UCP2 activation can also be elicited by lipid peroxidation end-products (45). According to these obseryations, UCIP2 is part of a neogative feedback mechanism that is able to respond to oxidative stress by controlling mitochondrial superoxide production.

\subsection{Tiseue distribution of UOPQ}

Initial work detected UCP2 mIRNA in a yariety of tissues (22, 23). Subsequent reports indicated particularly high UCP2 mIRNA expression levels in components of the immune system, such as the spleen, thymus, and macrophages (46-49). Anti-UGP2 antibodies have later become available, but some proved nonspecific when tested on tissues of UCP2/-mice (47). Further evaluation indicated that UCPZ miR A and protein levels do not al viays correlate and translational regulation of UCP2 may be significant (47). These considerations notwithstanding, UCP2 protein expression patterns in yarious tissues haye been fairly reliably mapped in studies using UCPZ-/- mouse tissues as negative control (31, 41, 49, 50$)$.

In contrast to the rather ubiquitous presence of UCPZ, hepatic UCP2 mIRNA expression has been localized to IXupffer cells (46), with yery low or undetectable levels in hepatocytes (46). In fetal rodent liver, UCP2 expression reached 30 times higher levels than in adults and UCP2 yas exclusively seen in hematopoietic cells by immunohistochemistry (51). It has been argued that high UCP2 expression levels in blood cell lineages, particularly in the monocyte/macrophage system, may confound the detection of UCP2 and could in fact account for its ubiquitous expression pattern (15). Hovever, immumohistochemistry helped to confirm the presence of UCP2 protein in adult mouse hepatocytes, predominanty 
in the periportal area (41). UCP2 expression was also detected in healthy and diseased hepatocytes in human percutaneous liver biopsy specimens (52). The latter study also found that UCP 2 was relatively abundant in bile duct cells of primary biliary cirrhosis, a finding of unkmown significance (52). It is curcently unlknown whether UCIPZ is expressed in other cell types of the liver such as stellate cells or sinusoidal endothelial cells.

The reason for unusually low UCP2 expression in normal hepatocytes remains puzzling and at this point we may only speculate of several explanations. Supply of ADP may be more abundant in the liver than in other tissues and a state 4-like respiration with unwanted oxidative stress is perhaps less likely to occur.

Differences in the mitochondrial inner membrane surface area and its fatty acid composition might allowy hepatocytes to adapt their basal proton conductance and ayoid mitochondrial hyperpolarization without significant contribution from protein-mediated proton lealx (53). Finally, there may be an as yet unlxnown protein that mediates proton conductance at baseline metabolic activity in hepatocytes. A liver-specific mitochondrial carrier protein has been recently isolated by comparative screening of CDNA libraries from IACO and paired normal liver tissue (54). This novel protein, termed HDDIM CP (HCO down-regulated mitochomdmial carrier protein), exhibits reduced expression in IICO and shows evolutionary conservation between humans, mice, and rats (54). Initial characterization shovys that IIDIICP, although it only shares an $25 \%$ homology with known uncoupling proteins, lowers $\Delta \Psi \mathrm{m}$ and reduces intracellular ATP levels when overexpressed in 2931 cells (54).

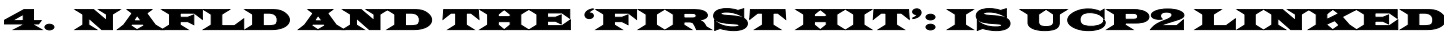
TO GINARTOEIS?

\subsection{Development of eteatoeis}

Fat is normally stored in the adipose tissue and not in the liver unless there is an imbalance betwreen lipid mobilization and lipid oxidation. Wh hen the capacity of hepatic lipid oxidation is exceeded, surplus lipids may be deposited in hepatocytes (Figure 2). Fatty acids in the liver may originate from dietary fat, release from the adipose tissue (lipolysis), or de novo synthesis (55). Fatty acids can be esterified into triglycerides and retransported into the circulation as yery lowy-density lipoproteins (VIDI) or deposited in the liver. Alternatively, fatty acids can be taken up into mitochondria facilitated by carnitine-palmitoyltransferase (CPT)-I, undergo beta-oxidation into acetylCoA and be further oxidized into carbon dioxide yia the tricarboxylic acid (TCA) cycle or serve as substrate for macromolecular symthesis and ketogenesis (56). These pathyays are intwicately tied to carbohydrate metabolism and form a complex regulation in which insulin has a pivotal function to decide on fuel preference betwyeen glucose and fatty acids (57). Although the most perceptible role of insulin is to secure euglycemia, it also regulates lipid metabolism (58). Insulin controls peripheral lipid mobilization by inhibiting hommonesensitive lipase, prevents secretion of YLDL from hepatocytes by increasing the degradation of apolipoprotein B-100 and blocking VIDL exocytosis, limits mitochondrial fatty acid uptake and beta-oxidation by inhibiting CPT-I, and promotes the synthesis of triglycerides by stimulating the transcription of lipogenic enzymes (58). 
Evidence shows that NAFID is associated with insulin resistance $(59,60)$. According to the original concept of glucose fatty acid cycle, fatty acids oppose peripheral glucose disposal by inhibiting key enzymes of glycolysis (61). This theory has recently been revisited and it appears that (at least in skeletal muscle and adipose tissue) fatty acids primarily impair insulin signaling and olucose uptake (62). These turo concepts agree in that large amounts of fatty acids from yarious sources (dietary intake, peripheral lipolysis, and de novo synthesis) are destined to generate insulin resistance (62). Importantly, there is a dichotomy among insulinregulated path ways of carbohydrate and lipid metabolism in which 'glucometabolic' insulin resistance is seen with excessive stimulation of lipogenic path ways that remain responsive to insulin (63). Thus, elevated plasma insulin levels may nurture hepatic fat accumulation and malxe the steatosis more severe. Interestingly, recent evidence shovys that hepatic components of insulin resistance correlate with steatosis and can be abrogated by preventing hepatic fat accumulation (64). A vicious cycle may therefore develop betwreen steatosis and insulin resistance.

\subsection{Regulation of UOP2 expression by fatty acide}

The association between UCP2 and lipid metabolism uras first noted by the ability of serum fatty acids to regulate the expression of ucp 2 gene. The same reports that initialiy identified ÚCPQ also demonstrated that white adipose tissue UCP2 transcript levels increased 4 to 6 fold following high-fat feeding (22) as well as in genetic models of obesity including the leptin-deficient ob/ob and leptin receptor-deficient db/db mice (23). A large number of studies on yarious tissues confirmed that UCP2 expression is generally increased in response to eleyated plasma fatty acid levels. Thus, in animal models baseline expression in hepatocytes is often yery small or

undetectable, but UCP2 shows significant up-regulation in the liver during pathologic conditions associated with eleyated plasma fatty acid levels and steatosis (65-68), supporting the view that the ucp 2 gene is regulated by fatty acids and lending credence to the purported involvement of UCP2 in the pathogenesis of fatty liver disease. In situ hybridization and immunohistochemistry performed on livers of ob/ob mice showed that expression of both UCP2 m 2 N A and protein is increased in hepatocytes compared to lean mice (65). In vivo lipid infusion caused UCF2 up-regulation in rats and in vitro exposure of primary cultured rat hepatocytes to lipids resulted in similar effects, indicating that excess UCP2 may indeed originate in hepatocytes as opposed to nonparenchymal liver cells (69). Finally, UCP2 expression increases considerably in the regenerating liver following partial hepatectomy ( 70,71$).$ Post-hepatectomy increase in plasma fatty acid levels (72) has been suggested to contribute to this surge of UClP2 expression (71).

Interestingly, the effect of yapious fatty acids on hepatic UCIP2 expression may be yery different. In rat hepatocytes, polyunsaturated fatty acids (PUEA) stimulated liver UCP2 m RNA levels much more than the monounsaturated oleic acid, while the saturated palmitic acid had virtually no effect (73). This differential effect of fatty acids most likely results from the complex interaction of fatty acid-regulated transcription factors and their direct and indirect effects on the ucp 2 gene. Peroxisome proliferator-activated receptors (PIPARs), a family of ligand-dependent nuclear transcriptional regulators involved in adipogenesis and lipid metabolism (74), may haye a key cole in transmitting the effects of 
fatty acids on hepatic UCP2 expression (73). The PPAR family has three major subtypes, PPAR $\alpha$, PIPAR $\gamma$, and PIPAR $\delta$, all activated by fatty acids and their depivatives (74). PPAIRs form active heterodimers with the retinoid X receptor and bind to PPAR-responsive elements (PPIE) in enhancer sites of regulated genes (74). PPAR $\alpha$ promotes hepatic fatty acid oxidation and ketogenesis, PPAR $\gamma$ is important in adipocyte differentiation and lipid storage Cpreferably in adipose tissue), and PPAR $\delta$ is inyolyed in cholesterol metabolism and fatty acid oxidation (74). Consequently, all three PPARs have been implicated in the amelioration of insulin resistance ( 75 ) and their impact on the course of NAFLD is of tremendous current interest. Direct or indirect stimulation of hepatic UOPQ expression may contribute to the effects of PPAIR in fatty liver disease. In yivo activation of PPAR $\alpha$ by diet rich in fish oil or by administration of its synthetic ligand, fenofibrate, results in several fold induction of UCPQ in mouse and rat hepatocytes (76). While the presence of PPAR $\gamma$ is insubstantial in healthy liver, its expression increases in rodent models of steatosis ( $7^{\prime} 7$ ) and administration of PREAR $\gamma$ ligands may induce UCP2 expression in fatty liver ( 78 ). It is worth noting that combination of high-fat diet with fenofibrate yas recently reported to induce de noyo expression of UCP3 protein in rat hepatocytes (79), indicating that PIPAR stimulation may be indeed a powerful tool to manipulate hepatic expression of uncoupling proteins.

\subsection{Impact of hepatic UOP2 expression on eteatosis}

Does increased hepatic expression of UCP2 have a beneficial or deleterious role in the development of steatosis? One plausible effect of enhanced UCIP function could be reduction of hepatocellular fat accumulation (Figure 2). First, it should be noted that interaction of UCPQ (and of other uncoupling proteins) with fatty acids seems to be a prerequisite for the 'uncoupling' function ( 80 ). In addition to their transcipiptional regulatory effects described earlier, fatty acids of yarying length and saturation may' 'activate' uncoupling proteins and this can be detected as proton lealk (80, 81). WV may consider tyo basic mechanisms by which UCAPQ action can potentially alleviate hepatic steatosis and the ensuing lipotoxicity. On the one hand, large amounts of fatty acids may enter the mitochondrial matrix and undergo beta-oxidation yielding excess NADI that needs to be re-oxidized by mitochondmial respiration. In case of fuel surplus, mitochondrial respiration may be limited by high proton greadient and become a bottleneclx (34, 82). UQP2-mediated proton leak may theoretically resolye this situation and support ongoing fatty acid oxidation as opposed to accumulation. On the other hand, fatty acids enter the matrix in the form of acyl-CoA (83) and insufficient INDI re-oxidation may result in the cleayage of more acyl-CoA into nonesterified fatty acids (NDFA) by matrix acyl-CoA

thioesterase (B4). NEFA cannot be further metabolized in the matrix or permeate the inner membrane and must be therefore actively transported out to the oytosol for further processing $(84)$. It is worth noting that intraceliular accumulation of fatty acids rather than triglycerides is deleterious and triglyceride formation may be in fact protective by converting saturated fatty acids that would otherwise induce apoptosis (85). UOP2 may therefore provide a translocation mechanism and prevent accumulation of NEFA and their hamm ful effects in the mitochomdrial matrix. 
Both mechanisms described above involve the interaction of UOCP 2 with fatty acids. Uncoupling proteins were first characterined as fatty acid transporters once the 'flip-flop' theory uras used to explain protein-mediated proton lealx (15). According to this hypothesis, uncoupling proteins transport fatty acids anions across the mitochomdrial inner membrane. Once in the intermembrane space, fatty acid anions join the protons extruded by respication and freely re-enter the matrix as non-polar molecules. Although formulated to understand ATP-independent inveard proton flux, 'flipflop' of fatty acids could also be interpreted as a means to free the matrix from accumulation of NEFA (86, 87). It has recently been suggested that a protective effect of novel uncoupling proteins could actually entail the translocation of even more deleterious fatty acid peroxide anions (B8). Therefore, if UCP2 mediates transports of fatty acid and fatty acid peroxides in the liver, it may have an important role in protecting the liver from hepatocellular lipotoxicity.

An intriguing and appealing aspect of how the novel uncoupling proteins may affect lipid metabolism is their potential link to AMIP-activated protein lxinase (AIVPIK). AMP IX phosphorylates a large number of key target proteins and acts as a pivotal metabolic regulator (89). In the liver, AMIPIX promotes fatty acid oxidation and ketogenesis while inhibits hepatic cholesterol biosynthesis and triglyceride formation (89). In peripheral tissues, AIVIX promotes fatty acid uptalke and oxidation while inhibits peripheral lipolysis and lipogenesis (89). Combined with its effects on glucose metabolism, AIVPIX powerfully steers metabolic path ways from energy accumulation to energy expenditure and fuel preference from glucose to fatty acids (89). Consequently, AMIPIX may improve insulin resistance and prevent hepatic fat accumulation. AMIPIK activation by AMIP involves direct allosteric stimulation, activation of an upstream kinase (AMIPIXIX), and inhibition of an inactivating phosphatase (89). AMIPIX activation is part of the insulin-sensitizing effect of adiponectin (90), a fat-derived bioactive protein found to haye reduced serum levels in NASIF and predict extensive necroinflammation in the liver (91). Since interference with efficient oxidative phosphorylation may be reflected by increased intracellular A IMP levels, it is reasomable to assume that uncoupling proteins contribute to AIMPIX activation. Indeed, increased expression of UCPI in transgenic mice has been shown to augment AMIP levels and AMIPIX activity in skeletal muscle (92) and in white adipose tissue (93). In mice overexpressing human UCPB, skeletal muscle UCPB protein levels six fold over the control viere associated with lowyer ATP/AMIP ratio and increased AMIPIX activity, presumably accounting for improved glucose tolerance (94). Although a parallel relationship between UCP2 expression and AMIPIX activity in fatty liver has been suggested (95), the validity of this link remains to be explored.

It came somewhat as a surprise that the degree of steatosis was essentialiy unchanged in livers of ob/ob mice and high fat-fed mice regardless of whether the ucp 2 gene was intact or dispupted (67). These negative findings cast a significant doubt on any perceivable role UCP2 may haye in the development of fatty liver. It must be emphasized, hoverere, that these data pertain to specific animal models and not to the pathophysiology of human NAFID. Also, mitochondrial fatty acid uptalke and a need for enhanced UCPZ action may be mitigated by the effect of high plasma insulin levels on CIPT-I activity, although diminished affinity of CPT-I to its physiological 
inhibitor, malonyl-CoA, has been reported in experimental diabetes (96). Neyertheless, UCPZ deficiency results in increased hepatic lipid accumulation when fatty acids originate from prolonged fasting and their mitochondrial uptake is not subject to the regulatory effect of insulin (97). To what extent may UCP2 help meet the need for increased beta-oxidation in the 'first hit' Of NAFLD characterized by 'ollucometabolic' insulin resistance (98) will require further elucidation.

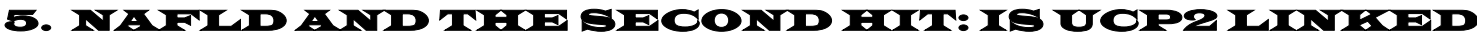
TO GTEATOLUEDATITIE?

\subsection{Oxidative streses and mitochondroial dyefunction in} NAFIUD

Elthough steatosis in most patients will not progress into adyanced liver disease, severity of steatosis appears to correlate with the progression of NAILD (99). Lipids accumulated in the liver are not inert and steatosis makes the liver more vulnerable to subsequent injury or a

'second hit' (11). Among the likely mechanisms, oxidative stress appears to have a prominemt role in this progression (99). There is increasing exidence in NAFLD for the dysfunction of mitochondria ( 59 , 100 , 101), which act not only as poyverhouse of the cell and key regulators of apoptosis, but are also considered a major source of intracellular reactive oxygen species (ROS) (32). Consequently, mitochondwial dysfunction may account for a number of pathologic processes that primarily characterize the steatohepatitis stage of NAFLD.

As discussed aboye (Figure 2), if large amounts of fatty acids enter the mitochoindria and undergo beta-oxidation, the respiration machinery slows down due to the stress imposed by increasing $\Delta \Psi$ m and superoxide production may increase significantly (34, 82). Moreover, rate of NADIA re-oxidation becomes relatively insufficient and the flux of beta-oxidation also decreases (83). Alternative fatty acid oxidation pathyrays in peroxisomes and microsomes may gain significance and lead to additional ROS production (102, 103). Potential feed-forward mechanisms that induce further mitochondrial injury and escalate oxidative stress include generation of toxic dicarboxylic acids by microsomal omega-oxidation (104), lipid peroxidation with the formation of reactive aldehydes (105), inhibition of ETC complexes directly by TN F-alpha and ceramide (106, 107 ) or due to oxidative damage of mitochondmial DIN that encodes several ETC subunits (108). Activity of all ETC complexes including the nuclear-oniy encoded complex II is decreased in patients with NASIA (108), suggesting that ROS may attack the mitochondrial membrane and impair functional assembly of the entice respiratory chain (106). Morphological studies also support the notion that mitochondria are a primary target in NASIH and prominent structural changes such as megamitochondria, paracristalline inclusions, and loss of mitochondrial cristae haye been reported $(59,101)$

5.2. NANIWD and cell-specific changes in hepatic UOPQ expreession

Fuel surplus due to high fatty acid load and a strained mitochondrial respiration that produces more superoxide may provide a plausible ground for the oxidative stress in hepatocytes typically seen in the steatohepatitis stage of NAJUD. One would expect that fat-laden hepatocytes might be protected from oxidative stress by the enhanced action of UCP2, a protein that 
limits mitochondrial superoxide production. Fovyeyer, oxidative stress persists in spite of increased hepatic UCP2 expression, at least in rodent models of fatty liver (109, 110). YYhile higher proton leak in mitochondria isolated from livers of ob/ob mice indicates that UCIP is operational (65), the rate of ROS production remains significantly increased in these organelles (109). The question why fatty liver in rodents is not protected from ROS production when it has such high levels of UCP2 expression seems difficult to answer. It is important to note that UCP2 expression during NAFLD in human liver is currenty unkmown. While studies that link ROS to UCP2 activation (44, 45) make it conceivable that UCP2 in fatty liver is not only highly expressed but also functional, there is no good evidence that U CP2 in turn would help to reduce ROS production and protect against steatohepatitis. WY may speculate that even increased amounts of UCP2 are not sufficient to control intracellular IROS generation in fatty liver. There is, hovever, an interesting phenomenon that may help to resolve this apparent paradox (Figure 3 ).

As noted earlier, UCP2 expression in normal liver dominates in Kupffer cells while it is rather limited in hepatocytes (46). Cuwiously enough, this pattern appears to revert in certain metabolic conditions. UCP2 expression is decreased and mitochondrial ROS is increased in peritoneal macrophages of ob/ob mice (1) 1 ). Endotoxin treatment causes similar changes in macrophages of lean mice (111). These observations indicate that the dramatically increased hepatocellular UCP2 expression in fatty liver is associated by a concomitant down-regulation of UCP2 in macrophages, a change that presumably extrapolates to Irupfifer cells. It is important to note that UCPQ expression in many studies was assessed in whole liver mitochondria (65, 109) and thus it may reflect the sum of opposing changes in parenchymal and nonparenchymal liver cells. UCP2 mRNA leyels diminished in non-parenchymal cells isolated by differential centrifugation from livers of rats fed fish oil or fibrate, although non-parenchymal cells of similarly treated mice shoured UCP2 m RN A upregulation (76). The need to separately analyze UCP2 expression in different liver cell types has been recently addressed with an elegant experimental design (31). Introduction of UCP2+/+ macrophages by bone marrow transplantation into UCPZ//- mice and a reverse strategy indicated that UOPZ expression in hepatocytes and liver macrophages is differentially altered in response to yarious challenges such as endotoxin exposure and atherogenic diet (31). It is easy to recognize that a similar mechanism may pertain to Kuppffer cells in NAFID. Therefore, if UCP2 indeed affects ROS production in steatohepatitis, this role must be related to its diminished expression in liver macrophages rather than to its augmented presence in hepatocytes.

Details of the negative transcriptional regulation of UCP2 in macrophages in response to endotoxin and obesity remain to be elucidated. Interestingly, an open reading frame (ORF) encoding a putative 36 amino acid peptide in exon 2 of the ucp 2 gene has been identified (47). Point mutation of start codons in this upstream ORF in COS cells results in significantly increased UCP2 expression (47). This sequence is conserved across yertebrates and similar ORFs were found in the 5'untranslated regions of several other mitochondrial carpier proteins (47). Additional evidence for cellspecific negative regulation of the ucp 2 gene was obtained on RAYY264 macrophages in which endotoxinstimulated signals interipupt an enhancer element 
localized to intron 2 , resulting in increased production of ROS and activation of nitric oxide synthesis (112).

\subsection{UOP2 and hepatocellulare energs Etatus in IANIUD}

While increased mitochondwial ROS production in steatohepatitis is presumably due to down-regulation of UCP2 in liver macrophages, it has been argued that upregulation of UCP2 expression in fatty hepatocytes could prove deleterious by interfering with ATP synthesis and causing energy depletion (65, 113). Although obesity per se does not appear to alter hepatic ATP stores (114), impaired ATP homeostasis in fatty liver has been observed following yarious challenges in both human and experimental settings. Graft failure occurs more often if liver transplantation is performed with fatty donor livers (115). Increased body mass index (BIII) correlated urith slower recovery of hepatic ATP content following fructose infusion in patients with biopsy-proven Ir ASI (116). In animal experiments, ATP content was diminished in rat liver when steatosis was induced by choline-deficient diet (117). Upon staryation of these animals, further and profound decrease in hepatic ATP stores was found ( 117 ). When ob/ob mice were exposed to transient hepatic ischemia and reperfusion, hepatic ATP stores that were already lover at baseline diminished dramatically upon the ischemic challenge and restored only partially by the end of reperfusion (65). It should be again noted that while increased UCP2 expression in experimental fatty liver of yarious origin has been demomstrated (65, 67, 68), there is currently no data on UCP2 levels in human fatty liver.

In summary, steatosis is likely to provide ofrounds for additional injury by increasing susceptibility of the liver to one or multiple 'second hits' during the progression of NAFID. Transcription of the fatty acid-responsive ucp gene undergoes significant changes in fatty liver and it appears that these changes are cell-specific. One the one hand, we may extrapolate from observations on macrophages that down-regulation of UCP2 also occurs in IXupffer cells, a change that may certainly contribute to increased ROS production and oxidative stress in steatohepatitis. One the other hand, up-regulation of UCP2 in hepatocytes may compromise energy homeostasis in these cells by possibly interfering with efficient ATP synthesis. However, these changes may not become manifest unless the liver faces additional challenges (ischemia and reperfusion, infection, etc.) and this may explain the absence of perceivable differences in obesity-related fatty liver of mice with and without UCP2 (67). If alteration of UCP2 expression has a potential to change the outcome of steatohepatitis, any planned interyention may conceivably need a cell-specific design.

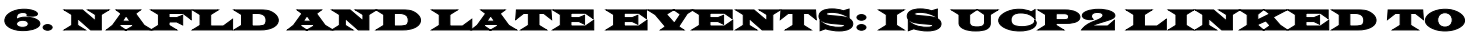
WIYAR OANOEZR?

\subsection{Obesity and liver cancer}

NAFLD may take an indolent course and progress into cirrhosis and I IC $(9,10)$. NASI and other features of the metabolic syndrome often precede 'cryptogenic' cirrhosis (10, 101). Mhile history of obesity in cryptogenic circhosis is an independent predictor of IEC (118), obesity even without ciprhosis appears to be a risk factor for the development of liver cancer. Perhaps the most strilking data on the link of obesity and I CC have been obtained in a prospective US Study assessing general cancer preyalence among more than 900,000 subjects wherein the relative risk for I IC of men and women with a BMI of 35 to 40 yas 4.52 and 1.68 , respectively 
(119). Experimental studies support these

epidemiological obseryations. Incidence of HCO is higher in ob/ob mice that have obesity and seyere steatosis (120). Since ob/ob mice do not develop ciprhosis, it was

suggested that not cirrhosis, but insulin resistance per se might be the cause of HCO in NAFLD (120). Growth effects of eleyated plasma insulin and insulin-like grourh factor-I levels, characteristic of insulin resistance, may indeed contribute to higher tumor rates in obesity (121).

\subsection{UOP2 as a modulator of apoptosie}

Most cancers result from an imbalance betwreen cell proliferation and cell death (122). IVitochondria occupy a central wole in the regulation of apoptosis (123). While the intwinsic apoptosis path way primarily responds to metabolic perturbations and intracellular oxidative stress, the extrinsic pathyray is activated through cell surface death receptors (123). There is evidence for crosstall between these two pathyrays and for mitochondwial involvement in both processes (123). Major apoptosis events include oligomerization of proapoptotic Bcl-2 proteins and their translocation to the mitochondria, permeabilization of the mitochondrial outer membrane, discuption of $\Delta \Psi \mathrm{m}$, release of intermembrane constituents (e.go, cytochrome c and apoptosis-inducing factor) into the eytosol, activation of initiator and executioner caspases, concluding into disassembly of the cell (123).

Based on its presumed biological functions, UCP2 may modulate apoptosis at seyeral checkpoints. One such checlxpoint may be mitochondrial hyperpolarization (MHP), a brief increase in $\triangle \Psi$ m that appears yery early in apoptosis and is often oyerlooked (Figure 4). MY IP was initially obseryed during the apoptosis of I Iymphocytes (124) and then demonstrated in yarious cell types including hepatocytes (125-127). MIF seems to initiate ROS production and thus may haye an important role in triggering apoptosis (126). Notably, apoptosis is delayed Or may not Occur if IVIIP (and subsequent ROS production) is preyented by mild uncoupling or by other measures (126, 128 ). Hoyveyer, it remains to be seen whether this mechanism accounts for the cytoprotective effect of in vitro and in yivo UCP2 overexpression.

\subsection{UOP2 and cancere cell adaptation to oxidative strese}

It has been knowy for many years that ROS production is increased in cancer cells (129, 130), but the significance of this finding is still poorly understood. IROS may elicit a wide range of cellular responses from proliferation to growth arrest to cell death (131). Under 'optimal' conditions, ROS may confer a gicourth advantage to tumor cells (130). Adverse environmental conditions such as nutritionai deprivation, hypoxia, and reduced substrate adhesion, hovreyer, may be detrimental to cancer cells by further increasing oxidative stress that is already at a higher level (130). Stimulation of ROS production in cancer may be exploited for therapeutic purposes and in fact many anticancer treatment modalities have been developed based on this concept (132). Recent anti-cancer treatment efforts specifically target cellular mechanisms that lead to increased ROS levels. Thus, enhancement of mitochondrial IROS production by the respiratory complex I inhibitor rotenone has been shown to increase apoptosis in human leukemia cells ( 133 ) and in fibrosarcoma cells (134). However, cancer cells may adapt to harsh conditions, become more tolerant to oxidative stress, and ayoid apoptosis (135, 136 ). 
Is there a link between increased expression of UCP2 and the propensity for I CO in NAFLD patients? In fact, there is very little known about the effects of UCP2 on carcinogenesis. In principle, even small changes in $\Delta \Psi \mathrm{m}$ and the rate of mitochondial ROS production affected by UCIP2 may cause significant shifts in the level of oxidative stress and in subsequent decisions on the fate of cancer cells. Drug-resistant subclones of yarious cancer cell lines that exhibit lover $\Delta \Psi \mathrm{m}$ are less susceptible to oxidative stress and express more UCP2 (137). This suggests that cancer cells may eventually use enhanced UCP2 function to gain survival adrantage. Expression of UCP2 in human colonic epithelium correlates with neoplastic changes along the adenoma-adenocarcinoma sequence, although UCP2 may serve here only as a marker of oxidative stress (4i). INore support for the role of UCP2 in cancer cell adaptation has been provided by studies in which high UCP2-expressing human cholangiocarcinoma cell lines vere more resistant to apoptotic stimuli than low UCD2-expressing cell lines (138). Furthermore, UCP2 expression was found continuously higher and $\Delta \Psi$ m loyver in primary cultured hepatocytes uyhen followyed up to 5 days (139). Increased UCEP2 expression yras also found in tyro out of four examined I CU cell limes and this coincided with hypomethylation of the ucp 2 gene (140). These studies suggest that increasing UCP2 expression may accompany hepatocyte dedifferentiation and coincide with reversion to a fetal phenotype of energy metabolism. Whether chronically high UCIPZ expression in NAINID contributes to the increased risk of HCO formation, howreyer, is presently unkmown.

In summary, it is an intriguing possibility to consider UCP2, a negative regulator of $\mathrm{R}$ OS production, to act as a modulator of apoptosis and a factor in the adaptation of cancer cells to oxidative stress. Further studies are needed to establish the role of UCP2 in cancer in general, and in NAFLD-related HCO formation in particular.

\section{OON OUUEIONE AND PEREIPEOTYYAS}

The relationship of UCPZ and NAFID appears to be more than serendipitous. For the time being, hoveryer, it is difficult to ayoid speculations and there is much to be elucidated. Most importantly, the biological functions and transcriptional regulatory mechanisms of UCP2 are still debated. Also, most of our knoviledge about the effects of UCPQ in liver disease is obtained from animal models not fully representative of human NAIID. In spite of these limitations, we may identify several areas in which UCP2 can contribute to the pathogenesis of NAFLD linked to the metabolic syndrome. In addition to promoting hepatic fat accumulation and insulin resistance, increased levels of plasma fatty acids and certain fat-derived bioactive factors increase UCP2 expression and activation in fatty liver. UUP2 may alter hepatic fat distribution and metabolism, but there is currently no convincing evidence that up-regulation of UCP2 has an impact on the development of steatosis. In line with the 'two-hit' theory of NAILD progiression, it seems more feasible that UCP2 contributes to transition of steatosis into steatohepatitis. UCP2 has the ability to affect hepatocellular bioenergetics upon additional challenges. Oxidative stress is a major pathogenic factor in steatohepatitis and UCP2 has been shown to control ROS production at their primary source in the mitochondrial respiratory chain. Recoǵnition of liver cell-specific regulation of UCP2 expression allovys us to differentiate these effects in parenchymal and non- 
parenchymal cells and supports customized strategies to modify UUCP2 transcription and function. Finally, UCP2 may mitigate ROS-triggered apoptosis and be a factor in the development of hepatocellular carcinoma related to obesity and insulin resistance.

\section{B. AOENOMLEDGMUENTE}

I yould like to thank members of my laboratory for critical reading of the manuscript and helpful

suggestions. This work yas supported by National Institutes of I Talth grants DIK-61890 and RIR-17695.

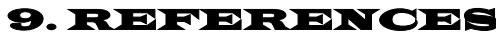

1. Mokdad, A. H., Serdula, M. IX., Dietz, WY. IF., Bownman, B. A., Marlxs, J. S. \& YXoplan, J. P.: The spread of the obesity epidemic in the United States, 1991-I998. JAMIA 282 , $1519-1522(1999)$

2. IKopelman, P. G.: Obesity as a medical problem. Nature $404,635-643(2000)$

3. DeFronzo, R. A. \& Ferrannini, E.: Insulin resistance. A multifaceted symdrome responsible for NIDIDI, obesity, hypertension, dyslipidemia, and atherosclerotic

cardioyascular disease. Diabetes Care 14, 173-1941 (1991)

4. Schaffner, F. \& Thaler, H.: Nonalcoholic fatty liver disease. Prog Liver Dis 8, 283-298 (1986)

5. Brunt, E. M.: Nonalcoholic steatohepatitis: definition and pathology. Semin Liver Dis 21, 3-16 (2001)

6. Nomura, I., Kashiwagi, S., IIayashi, J., IKajiyama, MY., Tani, S. \& Goto, IM.: Prevalence of fatty liver in a general population of Okinavia, Japan. Jpn.J.Med. 27, $142-149$ (1988)

7. Youssef, M. \& McCullough, A. J.: Diabetes mellitus, obesity, and hepatic steatosis. Semin Gastrointest Dis 13 , $17-30$ (2002)

8. IIIden, M., Christoffersen, P., Juhl, E. \& Dalgaard, J. B.: Liver histology in a normal population-examinations of 503 consecutive fatal traffic casualties. Scand $J$ Gastroenterol 12, $593-597$ (1977)

9. McCullough, A. J.: The clinical features, diagnosis and natural history of nonalcoholic fatty liver disease. Clin Liver Dis 8, $521-533$ (2004)

10. Marrero, J. A., Fontana, R. J., Su, G. L., Conjeevaram, H. S., Emick, D. IV. \& Lok, A. S.: NAFLD may be a common underlying liver disease in patients with hepatocellular carcinoma in the United States. Itepatology 36, 1349-1354 (2002)

11. Day, C. P. \& James, O. F.: Steatohepatitis: a tale of two hits? Gastroenterology 114 , 842-845 (1998)

12. Chitturi, S. \& Farrell, G. C.: Etiopathogenesis of nonalcoholic steatohepatitis. Semin Liver Dis $21,27-41$ (2001)

13. Browning, J. D. \& Horton, J. D.: Molecular mediators of hepatic steatosis and liver injury. J Clin Invest 114 , $147-152(2004)$ 
14. Boss, O., Hagen, T. \& Lowyell, B. B.: Uncoupling proteins 2 and 3 . Potential regulators of mitochondrial energy metabolism. Diabetes 49, 149-156 (2000)

15. Nedergaard, J. \& Cannon, B.: The 'novel' uncoupling proteins UUCP2 and UCPB: What do they really do? Pros and cons for suggested functions. Exp Physiol 88, 65-84. (2003)

16. Parascandola, J.: Dinitrophenol and bioenergetics: an historical perspective. Mol Cell Biochem 5, 69-77 (1974)

17. Mitchell, P.: Coupling of phosphorylation to electron and hydrogen transfer by a chemi-osmotic type of mechanism. Natururissenschaften 191 , $144-148$ (1961)

18. Nicholls, D. G. \& Ferguson, S. J.: Bioenergetics: An introduction to the chemiosmotic theory, 2 edition. Nexy York: Academic Press, (1992).

19. Brand, M. D., Brindle, K. M., Buckingham, J. A., Harper, J. A., Rolfe, D. F. \& Stuart, J. A.: The significance and mechanism of mitochondrial proton conductance. Int J Obes Relat Metab Disord 23 Suppl 6, S4-11 (1999)

20. Stuart, J. A., Cadenas, S., Jekabsons, M. B., Roussel, D. \& Brand, M. D.: Mitochondwial proton leak and the uncoupling protein 1 homologues. Biochim Biophys Acta 1504 , 144-158 (2001)

21. Ixlingenberg, IV.: Uncoupling protein-a useful energy dissipator. J Bioenerg Biomembir $31,419-430$. (1999)

22. Fleury, C., Neyeroya, M., Collins, S., Raimbault, S., Champigny, O., Levi-Meyrueis, C., Bouillaud, F., Seldin, IV. F., Survit, R. S., Ricquier, D. \& YYarden, C. I.: Uncoupling protein-2: a novel gene linked to obesity and hyperinsulinemia. Nat Genet 15, 269-272 (1997)

23. Gimeno, R. E., Dembski, M., Weng, X., Deng, N., Shyjan, A. YY., Gimeno, C. J., Iris, F., Ellis, S. J., YYoolf, E. A. \& Tartaglia, L. A.: Cloning and characterization of an uncoupling protein homoloğ: a potential molecular mediator of human thermogenesis. Diabetes 46 , $900-$ $906(1997)$

24. Bouillaud, F., Couplan, E., Pecqueur, C. \& Ricquier, D.: Iomologues of the uncoupling protein from browm

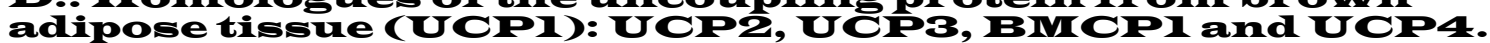
Biochim Biophys Acta 1504, 107-119. (2001)

25. Fleury, C. \& Sanchis, D.: The mitochondrial uncoupling protein-2: current status. Int J Biochem Cell Biol 31, $1261-1278$ (1999)

26. Irarper, J. A., Dickinson, IX. \& Brand, M. D.: Mitochondrial uncoupling as a target for drug developmemt for the treatment of obesity. Obes Rey 2 , 255-265 (2001)

27. Esterbauer, I., Schneitler, C., Oberkofler, II., Ebenbichler, C., Paulveber, B., Sandhofer, F., Ladurner, G., Iell, E., Strosberg, A. D., Patsch, J. R., Krempler, F. \& Patsch, $\mathrm{YY}$.: A common polymorphism in the promoter of UCP2 is associated with decreased risk of obesity in middle-aged humans. Nat Genet 28, $178-183$ (2001) 
28. Dalgaard, L. T. \& Pedersen, O.: Uncoupling proteins: functional characteristics and role in the pathogenesis of obesity and Type II diabetes. Diabetologia 44, 946-965 (2001)

29. Stuart, J. A., Harper, J. A., Brindle, IX. M., Jekabsons, IV. B. \& Brand, IV. D.: Physiological levels of manmmalian uncoupling protein 2 do not uncouple yeast mitochondria. J Biol Chem 276, $18633-18639$ (2001)

30. Jezelx, P., Zackova, M., Ruzicka, M., Skobisova, E. \& Jaburelx, IV.: Mitochondrial uncoupling proteins-facts and fantasies. Physiol Res 53 Suppl 1, S199-211 (2004)

31. Alves-Guerra, M. C., Rousset, S., Pecqueur, C., Mallat, Z., Blanc, J., Tedgui, A., Bouillaud, F., Cassard-Doulcier, A. IV., Ricquier, D. \& IVicoux, B.: Bone marroxy transplantation ceveals the in vivo expression of the mitochondrial uncoupling protein 2 in immune and non immune cells duringinflammation. J Biol Chem (2003)

32. Lenaz, G.: The mitochondrial production of reactive oxygen species: mechanisms and implications in human pathology. IUBMIB Life 52, 159-164 (2001)

33. St-Pierre, J., Buckingham, J. A., Roebuck, S. J. \& Brand, IV. D.: Topology of superoxide production from different sites in the mitochondwial electron transport chain. $J$ Biol Chem 277, 44784-44790 (2002)

34. Skulachey, Y. P.: Uncoupling: new approaches to an old problem of bioemergetics. Biochim Biophys Acta $1363,100-124$ (1998)

35. Okxuda, M., Lee, IT. O., IXumar, C. \& Chance, B.: Comparison of the effect of a mitochondmial uncoupler, 2,4-dinitrophenol and adrenaline on oxygen radical production in the isolated perfused rat liver. Acta Physiol Scand 145, 159-168 (1992)

36. Starkoy, A. A.: "Mild" uncoupling of mitochondria. Biosci Rep 17, 273-279 (1997)

37. Korshunov, S. S., Skulachey, Y. P. \& Starkoy, A. A.: Irigh protonic potential actuates a mechanism of production of reactive oxygen species in mitochomdria. FEIBS Lett 416, 15-18 (1997)

38. Mixya, S., St-Pierre, J., Partridge, L. \& Brand, M. D.: Superoxide and hydrogen peroxide production by Drosophila mitochondria. Free IRadic Biol MTed 35, 938948 (2003)

39. Negre-Salyayre, A., Hirtz, C., Carrera, G., Cazenaye, R., Troly, M., Salyayre, R., Penicaud, L. \& Casteilla, L.: A role for uncoupling protein-2 as a regulator of mitochondwial hydrogen peroxide generation. FASEIJ. $11,809-815(1999)$

40. Arsenijevic, D., Onuma, I., Pecqueur, C., Raimbault, S., Manning, B. S., IViroux, B., Couplan, E., Alves-Guerra, M. C., Goubern, M., Surwit, R., Bouillaud, F., Richard, D., Collins, S. \& Ricquier, D.: Disruption of the uncoupling protein-2 gene in mice reveals a role in immunity and reactive oxygen species production. Nat Genet $26,435-$ 439. (2000) 
41. Howimoto, M., Fulop, P., Derdalx, Z., Resmick, M., KYands, J. R. \& Baffy, G.: Uncoupling protein-2 deficiency promotes oxidant stress and delays liver regeneration in mice. It epatology 39, 386-392 (2004)

42. Teshima, Y., Akxao, M., Jones, S. P. \& Marban, E.: Uncoupling protein-2 overexpression inhibits mitochondrial death pathyyay in cardiomyocytes. Circ Res 93, 192-200 (2003)

43. Mattiasson, G., Shamloo, M., Gido, G., Mathi, KX., Tomasevic, G., Yi, S., YYarden, C. I., Castilho, R. I., Velcher, T., Gonzalez-Zulueta, M., Nikolich, IX. \&z MVieloch, T.: Uncoupling protein-2 prevents neuronal death and diminishes brain dysfunction after stroke and brain trauma. Nat Med 9,1062-1068 (2003)

44. Echtay, K. S., Roussel, D., St-Pierre, J., Jelkabsons, M. B., Cadenas, S., Stuart, J. A., Harper, J. A., Roebuck, S. J., Morpison, A., Pickering, S., Clapham, J. C. \& Brand, IV. D.: Superoxide activates mitochondrial uncoupling proteins. Nature 415, 96-99 (2002)

45. Echtay, K. S., Esteyes, T. C., Pakay, J. L., Jelkabsons, M. B., Lambert, A. J., Portero-Otin, M., Pamplona, R., Yidal-Puiğ, A. J., YYang, S., Roebuclx, S. J. \& Brand, IV. D.: A signalling role for 4-hydroxy-2-nonenal in regulation of mitochondrial uncoupling. EN $30 \mathrm{~J} 22,4103-4110$ (2003)

46. Larrouy, D., Laharrague, P., Carrera, G., ViguerieBascands, N., Lexi-Meyrueis, C., Fleury, C., Pecqueur, C., Nibbelink, M., Andre, IV., Casteilla, L. \& Ricquier, D.: Irupffer cells are a dominant site of uncoupling picotein 2 expression in rat liver. Biochem Biophys Res Commun $235,760-764$ (1998)

47. Pecqueur, C., Alves-Guerra, M. C., Gelly, O., LeviMeyrueis, C., Couplan, E., Collins, S., Ricquier, D., Bouillaud, F. \& IVicoux, B.: Uncoupling protein 2 , in vivo distribution, induction upon oxidativestress, and exidence for translational regulation. J Biol Chem 276 , 8705-8712. (2001)

48. Bechmann, I., Diano, S., Warden, C. I., Bartfai, T., Nitsch, R. \& Horyath, T. L.: Brain mitochondrial uncoupling protein 2 (UCP2): a protective stress signal in neuronal injury. Biochem Pharmacol 64, 363-367 (2002)

49. Zhang, C., Baffy, G., Perret, P., Krauss, S., Peroni, 0. Grujic, D., Iragen, T., Yidal-Puig, A. J., Boss, O., Kim, Y., Zheng, X. X., Wheeler, IV. B., Shulman, G. I., Chan, C. B. \& Lowell, B. B.: Uncoupling protein-2 negatively regulates insulin secretion and is a major link betwyeen obesity, beta cell dysfunction, and type 2 diabetes. Cell $105,745-755$ (2001)

50. Ixpauss, S., Zhang, C. Y. \& Lovell, B. B.: A significant portion of mitochondrial proton leak in intact thymocytes depends on expression of U CP2. Proc Nati Acad Sci U S A 99, $118-122$ (2002)

51. Hodny, Z., Kolaroya, P., Rossmeisl, IV., Horakova, M., Nibbelink, IM., Penicaud, L., Casteilla, L. \& Kopeclxy, J.: High expression of uncoupling protein 2 in foetal liver. FEISE Lett. 425, $185-190$ (1998) 
52. Taniguchi, E., Karada, M., Kavaguchi, T., Koǵ, K., IXumemura, K., Ianada, S., Shishido, S., Baba, S., Kumashixo, R., Ueno, T., Salxisaka, S. \& Sata, IV.: Expression of uncoupling protein-2 in biliary epithelial cells in primary biliary cirrhosis. Liver $22,451-458$ (2002)

53. Porter, R. IX., Hulbert, A. J. \& Brand, M. D.: Allometry of mitochondrial proton leak: influence of membrane surface area and fatty acid composition. Am J Playsiol 271, R1550-1560(1996)

54. Tan, M. G., Ooi, L. L., Avy, S. E. \& IYui, IX. M.: Cloning and identification of IIDIM CP, a novel liver-specific uncoupling protein that is downmegulated in human hepatocellular carcinoma. J Biol Chem (2004)

55. Saleh, J., Sniderman, A. D. \& Cianflone, K.: Regulation of Plasma fatty acid metabolism. Clin Chim Acta 286, $163-180(1999)$

56. Bartlett, IX. \& Eaton, S.: Mitochondrial beta-oxidation. Eur $J$ Biochem 271, $462-469$ (2004)

57. Ruderman, N. B., Saha, A. IX., Yayyas, D. \& YYitters, L. A.: Malonyl-CoA, fuel sensing, and insulin resistance. Am J Physiol 276, El-E18 (1999)

58. Saltiel, A. R. \& Kahn, C. R.: Insulin signalling and the regulation of glucose and lipid metabolism. Nature 414 , 799-806 (2001)

59. Sanyal, A. J., Campbell-Sargent, C., Mirshahi, F., Rizzo, YY. B., Contos, IV. J., Sterling, R. IX., Luketic, Y. A., Shiffman, M. L. \& Clore, J. N.: Nonalcoholic steatohepatitis: association of insulin resistance and mitochondrial abnormalities. Gastroenterology 120 , $1183-1192(2001)$

60. Paǵano, G., Pacini, G., Musso, G., Gambino, IR., Mecca, F., Depetris, N., Cassader, IV., David, E., CavalloPerin, P. \& Rizzetto, M.: Nonalcoholic steatohepatitis, insulin resistance, and metabolic syndrome: further evidence for an etiologic association. I Iepatology 35, 367$372(2002)$

61. Randle, P. J., Garland, P. B., Hales, C. N. \& Newsholme, E. A.: The glucose fatty-acid cycle. Its role in insulin sensitivity and the metabolic disturbances of diabetes mellitus. Lancet $1,785-789$ (1963)

62. Shulman, G. I.: Cellular mechanisms of insulin resistance. J Clin Invest $106,171-176$ (2000)

63. Unger, R. I.: Lipid overload and overflow: metabolic trauma and the metabolic symdrome. Frends Endocrinol Netab 14, 398-403 (2003)

64. Samuel, Y. T., Liu, Z. X., Qu, X., Elder, B. D., Bilz, S., Befroy, D., Romanelli, A. J. \& Shulman, G. I.: Mechanism of hepatic insulin resistance in non-alcoholic fatty liver disease. I Biol Chem 279, 32345-32353 (2004)

65. Chavin, IX. D., Yang, S., Lin, I. Z., Chatham, J., Chacko, Y. P., I Yoek, J. B., YYalajtys-Rode, E., Rashid, A., Ghen, C. It., Ituang, C. C., YYu, T. C., Lane, IV. D. \& Diehl, A. M.: Obesity induces expression of uncoupling protein-2 in 
hepatocytes and promotes liver ATP depletion. J Biol Chem 274, $5692-5700$ (1999)

66. Rashid, A., YYu, T. O., Iuang, O. O., Ghen, O. II., Lin, II. Z., Yango, S. Q., Lee, F. Y. \& Diehl, A. M.: Mitochondrial proteins that regulate apoptosis and necrosis are induced in mouse fatty liver. Ifepatology 29, $1131-1138$ (1999)

67. Baffy, G., Zhang, C. Y., Glickman, J. N. \& Lovyell, B. B.: Obesity-related fatty liver is unchanged in mice deficient for mitochondrial uncoupling protein 2. Iepatology 35, 753-761 (2002)

68. Starkel, P., Sempoux, C., Leclerco, I., Ierin, MI., Deby, C., Desager, J. P. \& Korsmans, Y.: Oxidative stress, IXIF6 and transforming growyh factor-beta up-regulation differentiate non-alcoholic steatohepatitis progressing to fibrosis from uncomplicated steatosis in rats. J Iepatol 39, $538-546(2003)$

69. Cortez-Pinto, H., Zhi Lin, I., Qi Yang, S., Odwin Da Costa, S. \& Diehl, A. M.: Lipids up-regulate uncoupling protein 2 expression in rat hepatocytes. Gastroenterology $116,1184-1193(1999)$

70. Lee, F. Y., Li, Y., Zhu, II., Yang, S., Lin, H. Z., Trush, MY. \& Diehl, A. M.: Tumor necrosis factor increases mitochond wial oxidant production and induces expression of uncoupling protein- 2 in the regenerating mice [correction of rat] liver. I Iepatology 29,677-687 (1999)

71. Yango, S. Q., Lin, H. Z., Mandal, A. IX., Iuang, J. \& Diehl, A. M.: Dismupted signaling and inhibited regeneration in obese mice vith fatty livers: implications for

nonalcoholic fatty liver disease pathophysiology. I Tepatology 34, 694-706 (2001)

72. Palmero, E., Ricart, D., Llobera, M. \& PeinadoOnsurbe, J.: Partial hepatectomy and/or surgical stress proyoke changes in the expression of lipoprotein lipase and actin in liver and extrahepatic tissues. Biochim Biophys Acta 1441, $61-68$ (1999)

73. Armstrong, IM. B. \& Toure, H. O.: Polyunsaturated fatty acids stimulate hepatic UUCP-2 expression via a PIA Ralpha-mediated pathyay. Am J Physiol Endocrinol Metab 281, E1197-12041 (2001)

74. Kersten, S., Desverǵne, B. \& W Yahli, MY.: Roles of PIPARs in health and disease. Nature $405,421-424$ (2000)

75. Moller, D. E. \& Berger, J. P.: Role of PPARs in the regulation of obesity-related insulin sensitivity and inflammation. Int J Obes IRelat Metab Disord 27 Suppl 3 , S17-21 (2003)

76. Nakxatani, T., Tsuboyama-Kasaoka, N., Takahashi, M., Miura, $\mathbf{S .}$ \& Ezaki, O.: Mechanism for peroxisome proliferator-activated receptor-alpha activator-induced up-regulation of UCEP $2 \mathrm{~m}$ UR A in rodent hepatocytes. $U$ Biol Chem 277, 9562-9569 (2002)

77. Rahimian, R., Masih-Ixhan, E., Lo, IV., yan Breemen, C., MoIManus, B. IV. \& Dube, G. P.: Hepatic overexpression of peroxisome proliferator activated receptor gammaz in the ob/ob mouse model of non-insulin 
dependent diabetes mellitus. Mol Cell Biochem 224 , 29 $37(2001)$

78. Memon, R. A., Tecott, L. II., Nonogaki, K., Beigneux, A., Moser, A. I., Grunfeld, C. \& Feingold, K. R.: Upregulation of peroxisome proliferator-activated receptors (PIAR-alpha) and PPAR-gamma messenger ribonucleic acid expression in the liver in murine obesity:

troglitazone induces expression of PPAR-gammaresponsive adipose tissue-specific genes in the liver of obese diabetic mice. Endocrinology 141,402141031 (2000)

79. Lanni, A., Mancini, F., Sabatino, L., Silvestri, E., Franco, R., De Rosa, G., Goglia, F. \& Colantuoni, Y.: De noyo expression of uncoupling protein 3 is associated to enhanced mitochondwial thioesterase-1 expression and fatty acid metabolism in liver of fenofibrate-treated rats. FEDS Lett 525, 7-12 (2002)

80. Echtay, K. S., Winkler, E. \& Kringenberg, M.: Coenzyme $Q$ is an obligatory cofactor for uncoupling protein function. Nature $408,609-613$ (200)

81. Zackova, M., Skobisova, E., Urbankoya, E. \&z Jezek, P.: Activating omega-6 polyunsaturated fatty acids and inhibitory purine nucleotides are high affinity ligands for novel mitochondrial uncoupling proteins UCP2 and UCF3. I Biol Chem 278, $20761-20769$ (2003)

82. Nobes, C. D., Hay, M. M., Jr. \& Brand, M. D.: The mechanism of stimulation of respiration by fatty acids in isolated hepatocytes. J Biol Chem 265, $12910-12915$ (1990)

83. Eaton, S.: Control of mitochondrial beta-oxidation flux. Prog Lipid Res 41, 197-239 (2002)

84. Hunt, M. C. \& Alexson, S. E.: The role Acyl-CoA thioesterases play in mediating intracellular lipid metabolism. Prog Lipid Res $41,99-130$ (2002)

85. Listenberger, L. L., Kan, X., Lewis, S. E., Cases, S., Farese, R. Y., Jr., Ory, D. S. \& Schaffer, J. E.: Triglyceride accumulation protects against fatty acid-induced lipotoxicity. Proc Natl Acad Sci U S A $100,3077-3082$ (2003)

86. IIimms-IIagen, J. \& I Harper, M. E.: Physiological role of UCPB may be export of fatty acids from mitochondria when fatty acid oxidation predominates: an hypothesis. Exp Biol Med (Maymood) 226, 78-84 (2001)

87. Schwaumen, P., Hoeks, J., Schaart, G., IXornips, E., Binas, B., Yan De Yusse, G. J., Yan Bilsen, M., Luiken, $J$. J., Coort, S. L., Glatz, J. F., Saris, MY. I. \&. \& Hesselink, M. IK.: Uncoupling protein 3 as a mitochondrial fatty acid anion exporter. FASEIB J17, 2272-2274 (2003)

88. Goglia, F. \& Skulachey, Y. P.: A function for novel uncoupling proteins: antioxidant defense of mitochondrial matrix by translocating fatty acid peroxides from the inmer to the outer membrane leaflet. PASEET J17, 1585-1591 (2003)

89. Carling, D.: The AMP-activated protein kinase cascade-a unifying system for enerós control. Trends Biochem Sci 29, 18-24 (2004) 
90. Yamauchi, T., Kamon, J., Minokoshi, Y., Ito, Y., MYaki, H., Uchida, S., Yamashita, S., Noda, M., IXita, S., Ueki, IX., Eto, IX., Alxanuma, Y., Froguel, P., Foufelle, F., Ferre, P., Carling, D., IXimura, S., Nagai, R., Kahn, B. B. \& Kadowaki, T.: Adiponectin Stimulates glucose utilization and fatty-acid oxidation by activating AMP-activated protein kinase. Nat Med 8, $1288-1295$ (2002)

91. Iuvi, J. M., Itodge, A., Farrell, G. O., Kench, J. G., Krilketos, A. \& George, J.: Beyond insulin resistance in NASII: TNIF-alpha or adiponectin? IFepatology $40,46-54$ (2004)

92. IIan, D. I., Nolte, L. A., Ju, J. S., Coleman, T.,

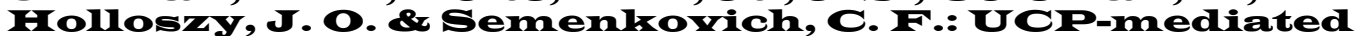
energy depletion in skeletal muscle increases glucose transport despite lipid accumulation and mitochondrial dysfunction. Am $J$ Physiol Endocinol Metab 286, E347$353(2004)$

93. Matejkova, O., Mustard, K. J., Sponarova, J., Flachs, P., Rossmeisl, M., Miksik, I., Thomason-Iughes, M., Grahame I Iardie, D. \& IXopecky, J.: Possible involvement of AIMP-activated protein kinase in obesity resistance induced by respiratory uncoupling in white fat. FEEBS Lett 569, 245-248 (2004)

94.. Schraumen, P., Hardie, D. G., Roorda, B., Clapham, J. C., Abuin, A., Thomason-Iughes, IV., Green, IX., Frederik, P. M. \& I I esselink, M. K.: Improyed glucose homeostasis in mice overexpressing human UCFB: a role for AMIP. kinase? Int $U$ Obes Relat Metab Disord 28, $824-828$ (2004)

95. Song, S.: Uncoupling protein-2: Evidence for its function as a metabolic regulator. Comment. Diabetologia $46,132-133(2003)$

96. Cook, G. A. \& Gamble, M. S.: Regulation of carnitine palmitoyltransferase by insulin results in decreased activity and decreased apparent Ixi yalues for malonylCoA. J Biol Chem 262, 2050-2055 (1987)

97. Fulop, P., KYands, J. R. \& Baffy, G.: UCP2 affects fasting-induced steatosis and metabolic parameters in lean and obese mice. Hepatology 36, 413A (2002)

98. Unger, R. I.: The hyperleptinemia of obesityregulator of calowic surpiuses. Cell117, $145-146$ (2004)

99. Day, C. P. \& James, O. F.: Kepatic steatosis: innocent bystander or guilty party? Ifepatology $27,1463-1466$ (1998)

100. Pessayre, D., Berson, A., Fromenty, B. \& Mansouri, A.: Mitochondria in steatohepatitis. Semin Liver Dis 21 , $57-69(2001)$

101. Caldwell, S. I., Swerdlow, R. I., IXhan, E. IM., Iezzoni, J. C., Iespenheide, E. E., Parks, J. Ix. \& Parker, YY. D., Jr.: Mitochondrial abnormalities in non-alcoholic steatohepatitis. J I Tepatol 31, 430-434 (1999)

102. YYeltman, M. D., Farrell, G. C., Hall, P., Ingelman-

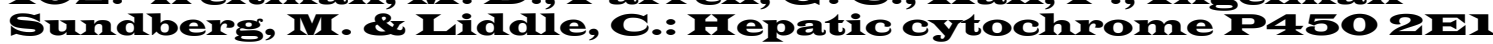
is increased in patients with nonalcoholic steatohepatitis. Iepatology 27, 128-133 (1998) 
103. Murphy, P. A., Kreahling, J. B., Gee, R., Kirk, J. R. \& Tolbert, N. E.: Enzyme activities of isolated hepatic peroxisomes from genetically lean and obese male mice. Arch Biochem Biophys 193, 179-185 (1979)

104. Tonsgard, J. II. \& Getz, G. S.: Effect of Reye's syndrome serum on isolated chinchilla liver mitochondria. J.Clin.Invest. 76, 816-825 (1985)

105. Leclerco, I. A., Farrell, G. C., Field, J., Bell, D. R., Gonzalez, F.J. \& Robertson, G. R.: CXYPEEI and CXYAA as microsomal catalysts of lipid peroxides in mumine nonalcoholic steatohepatitis. J Olin Invest $105,1067-$ $1075(2000)$

106. Lancaster, J. R., Jr., Laster, S. M. \& Gooding, L. R.: Inhibition of target cell mitochondwial electron transfer by tum or necrosis factor. FEIS Lett 248, $169-174$ (1989)

107. Garcia-Ruiz, C., Colell, A., Mari, M., Morales, A. \& Fernandez-Checa, $J$. C.: Direct effect of ceramide on the mitochondrial electron transport chain leads to seneration of reactive oxygen species. Role of mitochondrial glutathione. J Biol Chem 272, $11369-11377$ (1997)

108. Perez-Carreras, M., Del Hoyo, P., Martin, M. A., Rubio, J. C., Martin, A., Castellano, G., Colina, F., Arenas, J. \& Solis-Herruzo, J. A.: Defective hepatic mitochondrial respiratory chain in patients yith nonalcoholic steatohepatitis. Ifepatology 38, 999-1007 (2003)

109. Yang, S., Zhuu, H., Li, Y., Lin, YI., Gabrielson, IX., Trush, IV. A. \& Diehl, A. IV.: IVitochondrial adaptations to obesity-related oxidant stress. Arch Biochem Biophys 378, 259-268. (2000)

110. Soltys, Ix., Dikdan, G. \& Koneru, B.: Oxidative stress in fatty livers of obese Zucker rats: rapid amelioration and improyed tolerance to wamm ischemia with tocopherol. Iepatology 34, 13-18 (2001)

111. Lee, F. Y., Li, Y., Yang, E. YX., Yang, S. Q., Lin, I. Z., Trush, M. A., Dannemberg, A. J. \& Diehl, A. IV.: Phenotypic abnowmalities in macrophages from leptin-deficient, obese mice. Am $J$ Physiol 276, C386-394. (1999)

112. Krizaki, T., Suzuki, KX., Altomi, Y., Taniguchi, N., Saitoh, D., YYatanabe, IX., Onoe, IX., Day, N. IX., Good, IR. A. \& Ohno, I.: Uncoupling protein 2 plays an important role in nitric oxide production of lipopolysaccharideStimulated macrophages. Proc Natl Acad Sci U S A 99 , $9392-9397(2002)$

113. Yang, S. Q., Lin, I. Z., Lane, M. D., Clemens, M. \& Diehl, A. IM.: Obesity increases sensitivity to endotoxin liver injury: implications for the pathogenesis of steatohepatitis. Proc Natl Acad Sci U SA 94, 2557-2562 (1999)

114. Nair, S., V, P. C., Arnold, C. \& Diehl, A. M.: Iepatic ATP reserve and efficiency of replenishing: comparison betyreen obese and nonobese normal individuals. Am J Grastroenterol 98, $466-470$ (2003)

115. Clavien, P. A. \& Selzner, M.: Hepatic steatosis and transplantation. Liver Transpl 8, 980 (2002) 
116. Cortez-Pinto, I., Chatham, J., Chacko, Y. P., Ammold, C., Rashid, A. \& Diehl, A. M.: Alterations in liver ATP homeostasis in human monalcoholic steatohepatitis: a pilot study. JAMA 282, $1659-1664$ (1999)

117. Yendemiale, G., Grattagliano, I., Caraceni, P., Caraccio, G., Domenicali, M., Dall'Agata, M., Trevisani, F., Guerrieri, F., Bernardi, IV. \& Altomare, E.: IVitochondrial oxidative injury and energy metabolism alteration in rat fatty liver: effect of the nutpitional status. I Iepatology 33 , 808-815 (2001)

118. Nair, S., Mason, A., Eason, J., Loss, G. \& Perrillo, R. P.: Is obesity an independent risk factor for hepatocellular carcinoma in cirrhosis? I Lepatology 36, $150-155(2002)$

119. Calle, E. E., Rodriguez, C., Walker-Thurmond, K. \& Thun, MI. J.: Overyeight, obesity, and mortality from cancer in a prospectively studied cohort of U.S. adults. N Engl J Med 348, $1625-1638$ (2003)

120. Yang, S., Lin, H. Z., Iuvang, J., Chacko, V. P. \& Diehl, A. IV.: Iepatic hyperplasia in nonciprootic fatty livers: is obesity-related hepatic steatosis a premalignant condition? Cancer Res 61, $5016-5023$ (2001)

121. Bianchini, F., Kaaks, R. \& Yainio, H.: Overweight, obesity, and cancer wisk. Lancet Oncol 3, $565-574$ (2002)

122. Thompson, C. B.: Apoptosis in the pathogenesis and treatment of disease. Science $267,1456-1462$ (1995)

123. Green, D. R. \& Reed, J. C.: Mitochondria and apoptosis. Science 281, $1309-1312$ (1998)

124. Perl, A., Gergely, P., Jr., Nagy, G., Koncz, A. \& Banki, KX.: Mitochondrial hyperpolarization: a checkpoint of Tcell life, death and autoimmunity. Trends Immunol 25 , 360-367 (2004)

125. Iijima, T., Mishima, T., Alxagavya, KX. \& Ivyao, Y.: Mitochondrial hyperpolarization after transient oxyogenglucose deprivation and subsequent apoptosis in cultured rat hippocampal neurons. Brain Res 993, $140-145$ (2003)

126. Joshi, B., Li, L., Taffe, B. G., Zhu, Z., WYahl, S., Tian, I., Ben-Josef, E., Taylor, J. D., Porter, A. T. \& Tang, D. G.: Apoptosis induction by a novel anti-prostate cancer compound, BMIDI88 (a fatty acid-containing hydroxamic acid), requires the mitochondwial respiratory chain. Cancer IRes 59, 4343-4355 (1999)

127. Zili, D., Popox, Y., Patsenkex, E., Liu, C., YYand, X. D., Seitz, II. IX., Schuppan, D. \& Stickel, F.: Alcohol-related polar retinol metabolites are hepatotoxic due to apoptosis yia loss of mitochondrial membrane potential.

I Tepatology 40, 5704 (2004)

128. Matsuyama, S., Llopis, J., Deveraux, Q. L., Tsien, IR. Y. \& Reed, J. C.: Changes in intramitochondrial and cytosolic pII: early events that modulate caspase activation during apoptosis. Nat Cell Biol 2, 318-325 (2000) 
129. Hussain, S. P., Hofseth, L. J. \& Harris, C. C.: Radical causes of cancer. Nat Rey Cancer 3, 276-285 (2003)

130. Benhar, M., Engelberg, D. \& Levitzki, A.: ROS, stress-activated kinases and stress signaling in cancer. EMIBO IRep 3, 420-425 (2002)

131. Martindale, J. L. \& Holbrook, N. J.: Cellular response to oxidative stress: signaling for suicide and survival. J Cell Physiol 192 , $1-15$ (2002)

132. Biesalski, II. K. \& Frank, J.: Antioxidants in cancer therapy: is there a rationale to recommend antioxidants during cancer therapy? Biofactors 17, 229-2410 (2003)

133. Pelicano, I., Feng, L., Zhou, Y., Carevy, J. S., Hileman, E. O., Plunlxet, YY., Keating, M. J. \& I Iuang, P.: Inhibition of mitochondrial respiration: A novel strategy to enhance druginduced apoptosis in human leukemia cells by an ROS-mediated mechanism. J Biol Chem (2003)

134. Li, N., Raghelb, K., Lawyer, G., Sturóis, J., Rajura, B., Melendez, J. A. \& Robinson, J. P.: IVitochondrial complex I inhibitor rotenone induces apoptosis through enhancing mitochondrial reactive oxygen species production. J Biol Chem 278, $8516-8525(2003)$

135. Hersey, P. \& Zhang, X. D.: Overcoming resistance of cancer cells to apoptosis. J Cell Physiol $196,9-18$ (2003)

136. Igney, F. I. \& IKrammer, P. I.: Death and anti-death: tumour resistance to apoptosis. Nat Rey Cancer 2, 277$288(2002)$

137. I Iarper, M. E., Antoniou, A., Villalobos-Menuey, E., Russo, A., Trauger, R., Vendemelio, M., George, A., Bartholomevy, R., Carlo, D., Shaikh, A., Kupperman, J., Newell, E. WY., Bespaloy, I. A., KYallace, S. S., Liu, Y., Rogers, J. R., Gibbs, G. L., Leahy, J. L., Camiey, R. E., Melamede, R. \& Nevell, IV. IX.: Characterization of a novel metabolic strategy used by drug-resistant tumor cells. FASEI J16, $1550-1557$ (2002)

138. Berthiaume, E., Derdak, Z., Konkin, T. A., Resnick, M. B., YYands, J. R. \& Baffy, G.: Increased expression of uncoupling protein-2 in cholangiocarcinoma cells may confer resistance to apoptosis. Ifpatology 40 , 372A373A (2004)

139. Krimura, IX., Jung, B. D., Kanehira, IX., Irie, Y., Canas, X. \& Saito, M.: Induction of uncoupling protein (UCP) 2 in primary cultured hepatocytes. FNES Lett 457, 75-79 (1999)

140. Carretero, M. Y., Torres, L., Latasa, U., GarciaTrevijano, E. R., Prieto, J., Mato, J. IV. \& A vila, M. A.: Transformed but not normal hepatocytes express UCPQ. FEIBS Lett 439, 55-58 (1998) 
Figure I-Major determinante of mitochondrial membreane potential ( $\Delta \Psi \mathrm{mm})$

$\Delta \Psi \mathrm{m}$ is the result of proton translocation from mitochondwial matrix to intermembrane space by the electron transport chain (ETC) that includes complexes I to IY and mobile electron carrier proteins ubiquinone (U) and cytochrome c (C). ETC is supplied by reducing equivalents primarily formed during combustion of glucose and fatty acids. $\Delta \Psi \mathrm{m}$ is consumed through oxidative phosphorylation mediated by ATP synthase (FoFI) and through proton leak mediated by carrier proteins (UCP2 shovin here) and by basal proton conductance (BPC). Production rate of superoxide (02-.) at yarious ETC sites correlates with $\Delta \Psi \mathrm{m}$ explaining why processes that consume the proton gradient may alleviate mitochondrial oxidative stress.

Figure 2-Potential effects of UOPQ on fatty acid metabolism in NATFL

Large amounts of fatty acids (FA) are ayailable in NAFLD that enter mitochondria of hepatocytes as FACoA, undergo beta-oxidation, and yield ketones or oxidize fully within the tricarboxylic acid cycle (TCA). This fuel surplus feeds reducing equivalents into ETC and drives up $\Delta \Psi \mathrm{m}$, promoting $\mathrm{ROS}$ production and shifting excess FA into alternative pathyrays. These include increased synthesis of triglycerides leading to ectopic fat accumulation as yell as oxidation of fatty acids in nonmitochondrial compartments of the cell. FA may be freed of CoA by hydrolysis and trapped in the matrix as anions (FA-). Interaction of ROS with accumulated FA may produce lipid peroxide anions (I OO-FA-), similarly trapped in the matrix. In principle, UCPQ may alleviate these consequences by reducing $\Delta \Psi \mathrm{m}$ and the rate of $\mathrm{R}$ OS production and allowing efficient mitochondrial betaoxidation. UCP2-mediated proton leak may in fact occur through FA 'flip-flop' moving either FA- or KOO-FAanions across the inner membrane. FA 'flip-flop' may also result in removal of trapped FA- and FOO-FA- anions from the matrix.

Figure 3-Consequences of cell-specific hepatic UOPQ expreserion in INATHD

Opposing regulation of UCP2 expression may occur in non-parenchymal and parenchymal liver cells duping NAFLD. UCP2 in normal liver tissue is primarily detected in Irupffer cells and is scarcely present in hepatocytes. This cell-specificity appears to swap in fatty

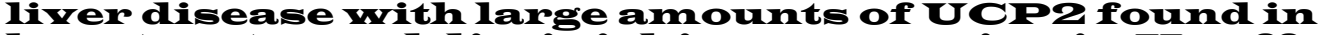
hepatocytes and diminishing expression in Ixupffer cells and other macrophages. Based on the presumed functions of UCP2, IXupffer cells appear to be a key source of oxidative stress in NAFID, while increasing competition of UCP2-mediated proton leak may contribute to impaired hepatoceliular bioenergetics. Details of the transcriptional regulation of UClP2 remain to be seen.

Figure 4-Iypothetical model for the link between UOPQ and carcoinogenesie

A vide spectrum of cell fate outcomes is associated with ROS production and includes such extremes as autonomous proliferation and destruction of the cell (inset). Cancer formation is normally offset by apoptosis in which IR OS-mediated mitochondrial outer membrane 
permeabilization (IVOIMP) is often a point of no return, leading to cytochrome c release into the cytosol and activation of the caspases cascade. Mitochondria provide much of intracellular ROS and this process is yery

sensitive to changes in $\Delta \Psi m$. Apoptosis is often initiated by a surge in ROS resulting from an early increase in $\Delta \Psi \mathrm{m}$ and UCP2 may in principle mitigate this brief mitochondwial hyperpolarization. Therefore, even subtle shifts in $\Delta \Psi$ m could modulate apoptosis and tilt the balance of ROS effects toward cancer formation. This model may be valid in NAFID where prolonged elevation of UCP2 expression in hepatocytes would contribute to the development of liver cancer. 
Figure 1

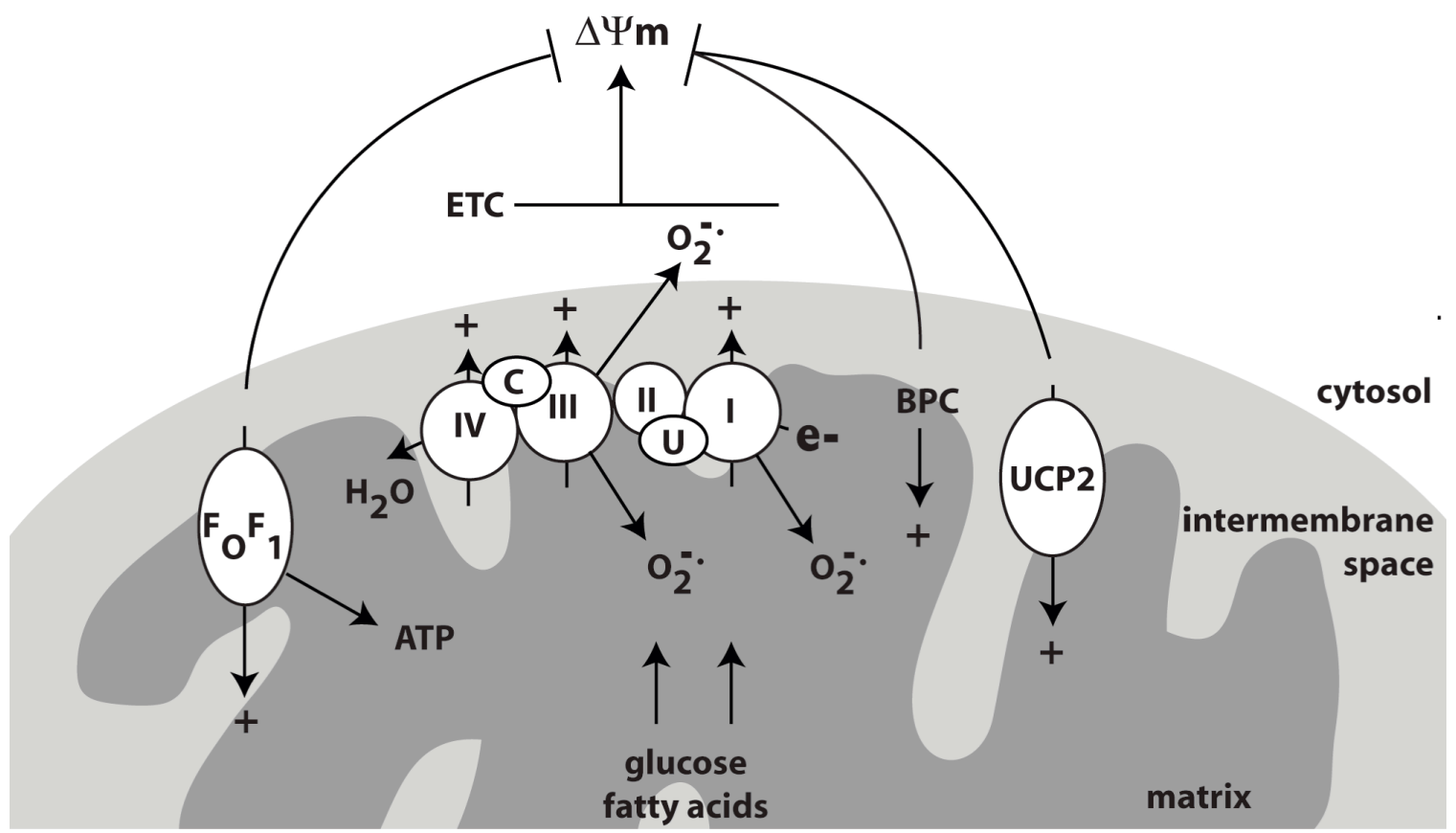




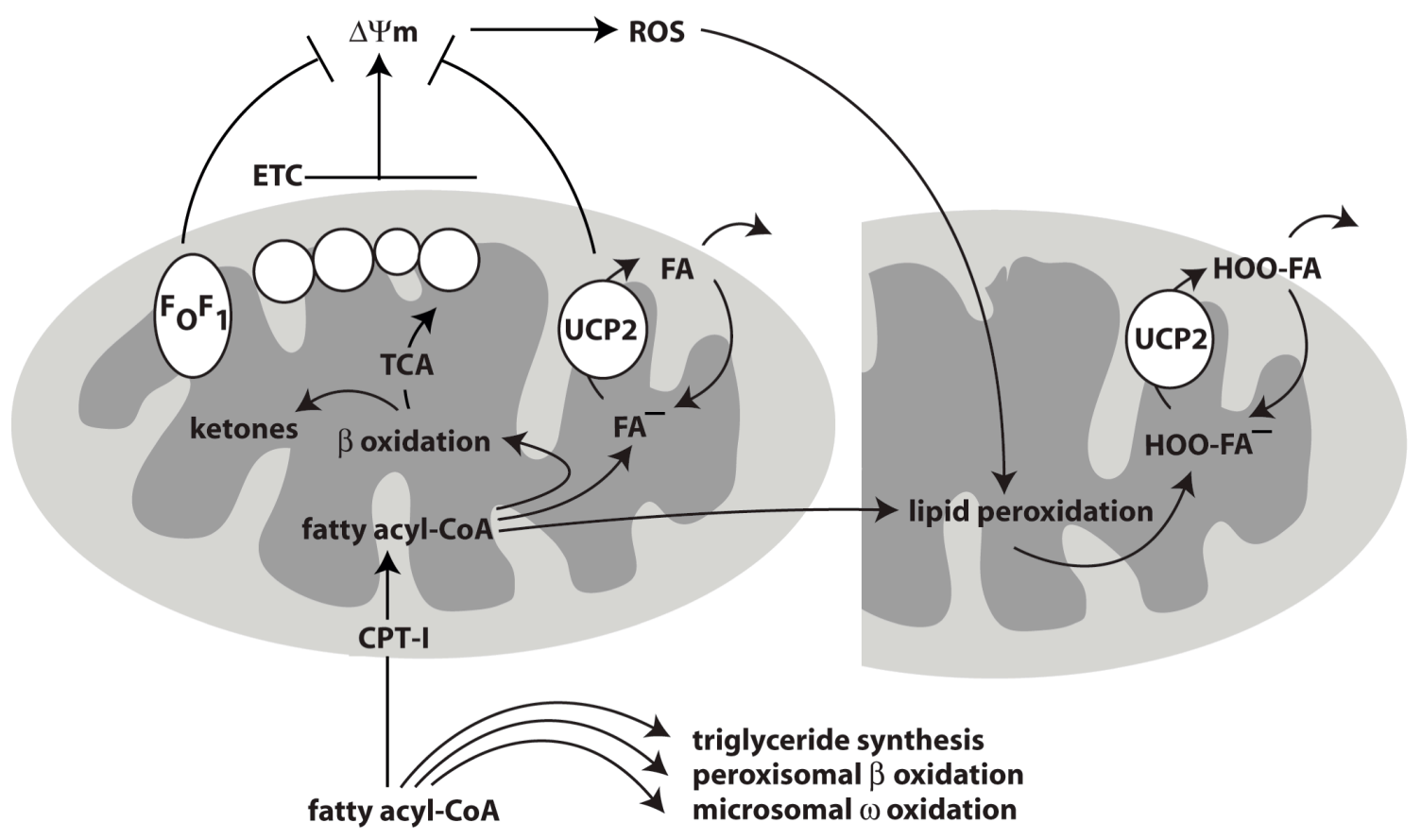


Figuree 3

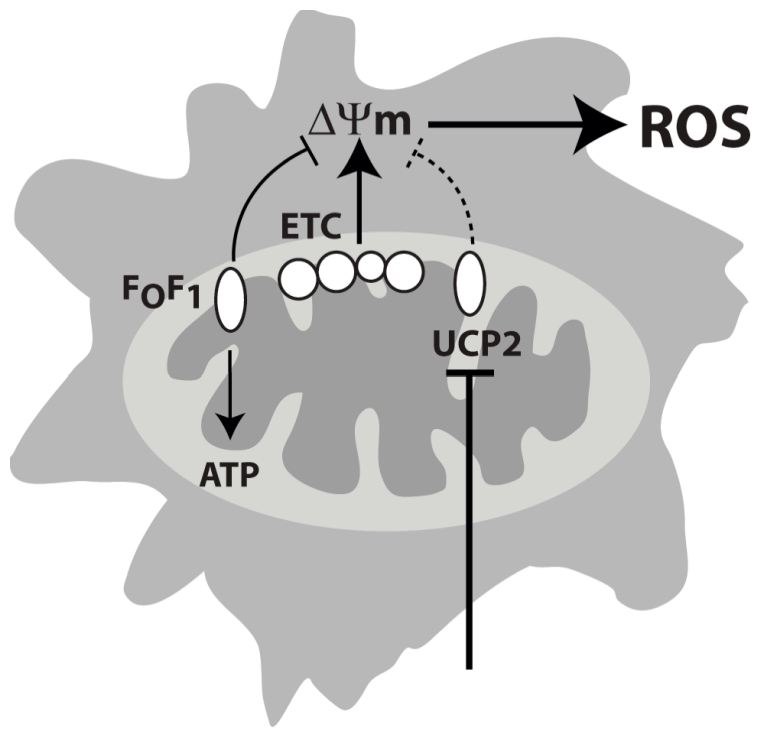

Kupffer cells

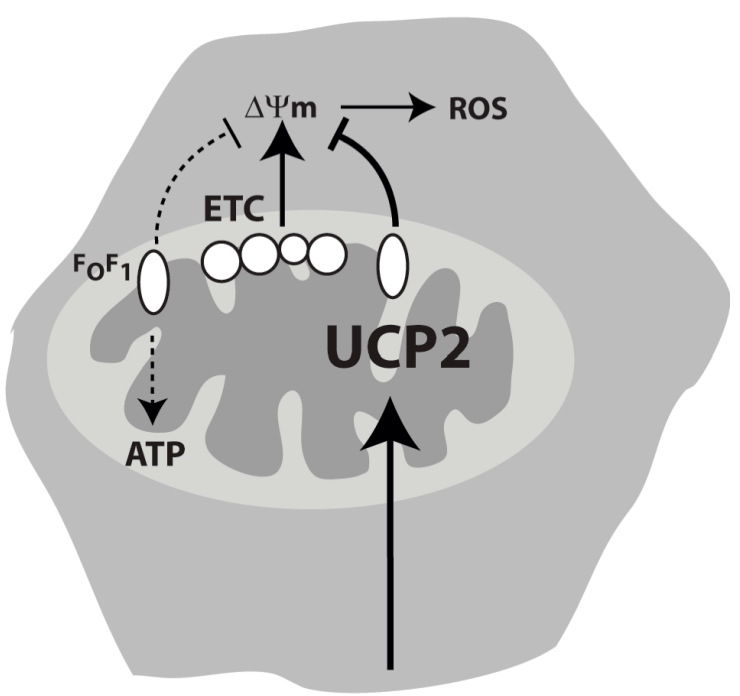

Hepatocytes 


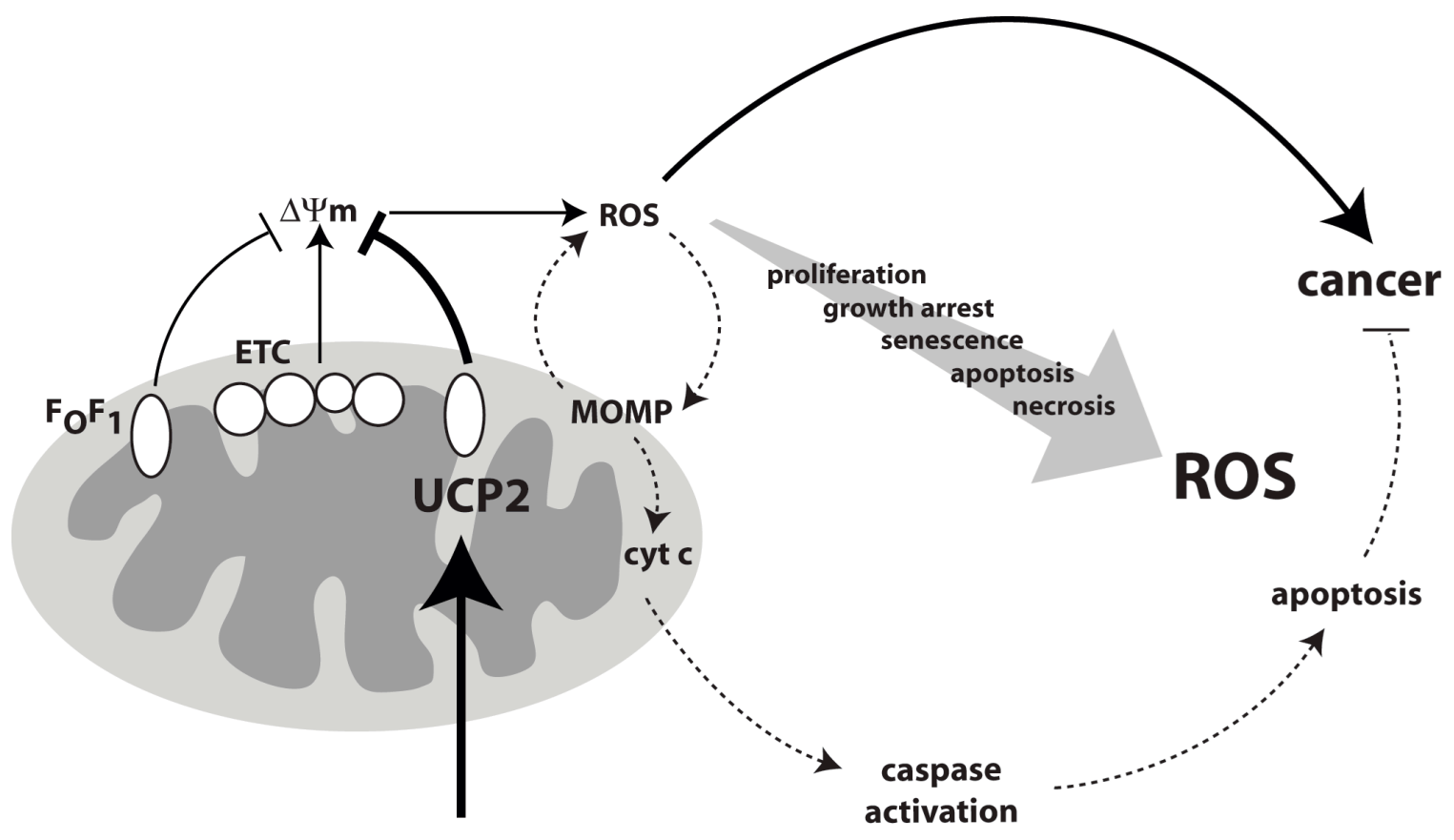


Gend correspondence to: Györogy Baffy, M.D., Ph.D., Liver Research Center, 55 Clayericlx Street, Room 413 , Providence, RI 02903. Tel: (401) 444-2536, Fax: (4101) 444-2939, E-mail: gbaffy@brown.edu

Rumning title: UOP2 and NAFLD

IKey words: uncoupling protein-2, mitochondria, electron transport chain, oxidative phosphorylation, proton leak, mitochondrial membrane potential, reactive oxygen

species, fatty acids, AMIP-activated lximase, non-alcoholic fatty liver disease, non-alcoholic steatohepatitis,

cryptogenic cirrhosis, hepatocellular cancer 